\title{
Computational Modelling of Noise Pollution and Its Health Hazard Using Probability Distribution Models: A Systematic Review
}

\author{
Ali Danladi ${ }^{1}$, Ibrahim Goni ${ }^{*}$, Bulus Bali ${ }^{2}$, Nathan Nachandia ${ }^{3}$, Aiyu B. Dahiru ${ }^{4}$ \& Jerome M. Gumpy ${ }^{4}$ \\ ${ }^{1}$ Department of Pure and Applied Physics, ${ }^{1,2,3}$ Department of Computer Science, Adamawa State University, Mubi, Nigeria. \\ ${ }^{4}$ Department of Computer Engineering, Federal Polytechnic, Mubi, Nigeria. \\ ${ }^{4}$ Department of Computer Science, Federal University, Gashua, Nigeria. \\ DOI: http://doi.org/10.38177/AJBSR.2021.3207
}

Crossref

Copyright: (02021 Ali Danladi et al. This is an open access article distributed under the terms of the Creative Commons Attribution License, which permits unrestricted use, distribution, and reproduction in any medium, provided the original author and source are credited.

\section{ABSTRACT}

Noise pollution is one of the man-made environmental hazards after air, water and land pollution that is given the least attention by the World Health Organization (WHO). Noise pollution is an excessive sound produce intentionally or accidently that can have deleterious effects on human and animal's health and even environmental quality. The major Sources of this sound are industries, highways, railways, and aircraft traffic and entertainment cafes. This research work was to conduct systematic review regarding the application of probability distribution models and other computing techniques in modelling the effects of extensive sound in human health and also the critical level of sound to human exposure as compare to WHO standard.

\section{Background}

Noise pollution (NP) is considered as the third most hazardous type of environmental pollution. High noise pollution in residential areas is recognized in the world as a major threat to health and affecting liveability Min \& Min (2017); Foraster et al., (2018); Alnuman \& Ghnimat (2019); Lim \& Thurston, (2019); Oguntunde et al., (2019); Weihofen et al., (2019); Jensen \& Ekholm, (2019); Basner, Witte \& McGuire, (2019); Huang et al., (2019); Dreger et al., (2019); Basner et al., (2020); Shin et al., (2020); . Major sources of noise can be traced to moving vehicles Babish (2014); Halonen et al., (2015); Foraster et al., (2018); Basner, Witte, \& McGuire, (2019); Brown, Lam, \& Kamp, (2015). Individual and community activities Ali, (2011); Xingsong et al., (2020). In fact, it is noticed that about $70 \%$ of environmental noise generated by moving vehicle caused due to engine and exhaust systems Clara et al., (2018). It is also believed that noise pollution can be pose health hazard on human beings such as sleep disturbance, stress, mental disorder, cardiovascular disorder and loss of hearing, etc.

Le et al., (2017); Basner, Witte \& McGuire, (2019); Rudolph et al., (2019); Li et al., (2019). Quite a number of studies on noise pollution has been carried out for example, Kumar et al., (2011) conducted a research on mathematical modeling of road noise using regression analysis and reported that their model can be used for noise prediction. Gollamandla et al., (2017), used Microsoft excel and developed a model that recognizes the dependences of the intensity noise. Ify and Ofem (2014), utilized linear, quadratic and cubic curves fitting and predicted there is high of correlation between traffic volume and noise pollution, also calculated that noise level on express way in about 113dB (A). Akirnay et al., (2007) suggested that sound propagation can be influenced by metrological or weather parameters such as wind and temperature gradient. Okoro et al., (2016) in their study stated sound level increase in commercial areas especially in timber industry. According to Priyanka et al. (2015) noise pollution can cause health hazard more than just hearing disorder and that NP is liable to cause other health problems like blood pressure, tiredness and increase blood pressure cholesterol. 
However, in Nigeria most commercial areas such as market area constructed right in the heart of the cities, milling and timber industries some are built zero meter from residential areas, this research is carried out to estimate the noise pollution level in residential areas. Whereas the following challenges shall be address to model and estimate the amount of noise level of different activities in residential area to determine the probability of exceeding critical point of specific health hazards, and compare the noise level estimated with the world health organization (WHO).

Table 1. Depicts some environmental noise exposure and correspond health hazards

\begin{tabular}{|ccc|}
\hline Health Hazards & Noise (dB) & Exposure Time (Hours) \\
\hline Hearing impairment & $70-75$ & $1-4$ \\
Hypertension & 70 & 8 daily \\
Ischemic heart disease & 70 & 8 daily \\
Annoyance & 42 & 16 daily \\
Performance & 70 & 8 daily \\
Sleep disturbance pattern & $<60$ & Any time \\
Mode next day & $<60$ & 10 daily \\
\hline
\end{tabular}

Source; Paschier, Vermeer and Passcheir (2000)

Moreover, WHO, (1999) they further summarize the maximum exact values that can cause theses disease like; hearing impairment is $70 \mathrm{~dB}$, speech intelligibility is affected by a maximum of $35-50 \mathrm{~dB}$, sleep disturbance is causes by a maximum of $30-45 \mathrm{~dB}$, psychological function is disturbed by a maximum industrial noise of 5-30dB, mental illness in this exposure of high level of occupational noise can cause neurosis, annoyance can cause by a maximum of $50 \mathrm{~dB}$,

\section{Literature}

Noise is an unwanted sound (Kyoung \& Jin-Young, 2017) unpleasant sound (Xingsong et al., 2020) which disturb, discomfort, stress human beings and animals, physically, physiologically and psychologically. Many researches have extensively evaluated the health risk of short-term exposure and long-term exposure to noise ( Cathryn et al., 2016; casaroni et al., 2014; Beelen et al., 2014; Foester et al., 2017; Pyko et al., 2017). In urban setting, where road traffic, railway traffic, milling machine and block industry are the important sources of ambient noise pollution which are extensively associated with the major disease in question (Xingsong et al., 2010; Zhu et al., 2017; Levigre et al., 2016; Honda et al., 2017; Hu et al., 2014; Perdersen et al., 2014). The effect of noise includes hypertension mental disorder, cardiovascular disease, social behaviour disorder, sleep disturbance, infertility, spontaneous abortion, congenital malfunctions, and hearing impairment (Kyoung and Jin-Young 2020; Basner et al., 2014; Chamkori et al., 2016; Eisenberg et al., 2015; Wqgam et al., 2016; Collen et al., 2019; Garcia, Smith \& Palmer, 2018; Barsner \& Mcgure 2018). Moreover, the thinking capability, productivity of the workers, human performance and intellectual functionality are also confirmed to be affected by noise as the studies explored (Barsner et al., 2014; DEFA, 2014; Tzivian et al., 2015). 
Sleep disorder is one of the major concerns in human and animal life however, studies suggested that long time exposure to noise may cause postromantic stress disorder, sleep disorder and other related issues as in (Van Kampen et al., 2018; Zare Skhvidi et al., 2018; Pyko et al., 2017; Bersner \& Mcguire, 2018; Munzel et al., 2016). The high severity level in sleep disorder may lead to chronic endocrine and nervous system alteration as the studies shows (Mumzel et al., 2017; Recio et al., 2016).

Table 2.Systematic Review of some specific effects of exposure to excessive environmental noise

\begin{tabular}{|c|c|c|}
\hline $\mathbf{S} / \mathbf{N}$ & Author (s) and Year & Effect \\
\hline 1. & Correia, et al., 2013 & Cardiovascular risk \\
\hline 2. & de Kluizenaar, et al., 2013 & Cardiovascular risk \\
\hline 3. & Guzik \& Channon 2017 & Cardiovascular risk \\
\hline 4. & Hahad et al., 2019 & Cardiovascular effect of noise \\
\hline 5. & Li et al., 2019 & Cardiovascular and Hearing \\
\hline 6. & Münzel, et al., 2014 & Cardiovascular risk \\
\hline 7. & Münzel et al., 2018 & Cardiovascular system \\
\hline 8. & Münzel et al., 2018 & Cardiovascular risk \\
\hline 9. & Recio, et al., 2016 & cardiovascular, respiratory and metabolic health \\
\hline 10. & Stansfeld \& Clark 2015 & Psychophysiological effects \\
\hline 11. & Swinburn, Hammer \& Neitzel, 2015 & Cardiovascular health hazard \\
\hline 12. & Tabraiz et al., 2015 & Psychophysiological effects \\
\hline 13. & Tobías et al., 2015 & Cardiovascular risk \\
\hline 14. & Basner et al., 2020 & Hypertension and diabetes mellitus \\
\hline 15. & Lim \& Thurston, 2019 & Diabetes \\
\hline 16. & Liu et al., 2018 & Diabetes \\
\hline 17. & Shin et al., 2020 & Diabetes mellitus and hypertension \\
\hline 18. & Taban, 2016 & Diabetes \\
\hline 19. & Yang et al., 2018 & Diabetes \\
\hline 20. & Zare Sakhvidi, 2018 & Diabetes \\
\hline 21. & Babisch, et al., 2014 & Hypertension \\
\hline 22. & de Souza, 2015 & Hypertension \\
\hline 23. & de Souza, Périssé \& Moura 2015 & Hypertension \\
\hline 24. & Fajar et al., 2019 & Hypertension \\
\hline 25. & 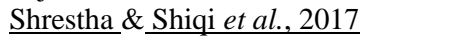 & Hypertension \\
\hline 26. & Alnuman \& Ghnimat 2019 & Hearing loss \\
\hline 27. & Helzner \& Contrera, 2016 & Diabetes and hearing impairment \\
\hline 28. & Le et al., 2017 & Hearing loss \\
\hline 29. & Lie et al., 2016 & Hearing loss \\
\hline 30. & Oguntunde et al., 2019 & Hearing loss \\
\hline 31. & Russ et al., 2017 & Hearing loss \\
\hline 32. & Sareen \& Singh 2014 & Hearing loss \\
\hline 33. & Lusk et al., 2016 & Stroke \\
\hline 34. & Stokholm 2013 & Stroke \\
\hline 35. & Vivanco-Hidalgo et al., 2018 & Stroke \\
\hline 36. & Vivanco-Hidalgo et al., 2019 & Stroke \\
\hline 37. & Weihofen et al., 2019 & Stroke \\
\hline 38. & Babisch, 2014 & Coronary heart diseases \\
\hline 39. & Banerjee, Das \& Foujdar, 2014 & Coronary heart diseases \\
\hline 40. & Foraster et al., 2018 & Adiposity markers and development of obesity \\
\hline 41. & Beutel et al., 2016 & Depression and anxiety \\
\hline 42. & Orban et al., 2016 & Depression \\
\hline 43. & Alimohammadi, et al., 2013 & Mental performance \\
\hline 44. & Clark \& Paunovic, 2018 & Mental health \\
\hline 45. & Dzhambov et al., 2018 & Mental health \\
\hline 46. & Helbich, 2018 & Mental health \\
\hline 47. & Lim et al., 2018 & Mental health \\
\hline 48. & Jensen \& Ekholm, 2019 & Mental and physical health \\
\hline 49. & Rudolph et al., 2019 & Sleep and mental health \\
\hline 50. & Tzivian et al., 2015 & Cognitive and psychological functions \\
\hline 51. & Basner \& McGuire, 2018 & Sleep disturbance \\
\hline 52. & Basner, Witte \& McGuire, 2019 & Effects on sleep \\
\hline 53. & Brown, Lam \& Kamp, 2015 & Sleep disturbance \\
\hline 54. & DEFA, 2014 & $\begin{array}{l}\text { Sleep disturbance, annoyance, hypertension, productivity } \\
\text { and quiet }\end{array}$ \\
\hline 55. & Delaney, Haren \& Lopez, 2015 & Sleep disturbances \\
\hline
\end{tabular}


Demian, (2014) has also added how noise disturbance has become threat to health apart from sleep disturbance some research shows that long term exposure to environmental noise lead to daytime sleepless and tiredness, mood changes, cognitive performance and decrease wellbeing (Muzet 2007; Bersner 2008; Babiseh et al., 2009; Elmenhorst et al., 2010; Golnes \& Hagler, 2007).

Infertility is a failure to reproduce naturally. According to European society of human reproduction and embryology 2014 believed that infertility affect couples with $20-30 \%$ from male and $20-30 \%$ due to female infertility. Moreover, 25-40\% occurred from the both. Although the causative agent have remained a major concern among researchers some studies indicates that long exposure to noise may cause infertility for both males and females (Kyoung \& Jin, 2017) and similarly (Vested et al., 2014; Kenz 2013; Mocarell et al., 2008; Eisenberg et al., 2015; Farzadinia 2016; Julia et al., 2013; Hart 2016).

Recently, several studies has shown that long term exposure to noise mental disorder can cause psychological retardation or disorder (Pun et al., 2017; Zijlema et al., 2016; Orban et al., 2016; Selder et al., 2017; Vert et al., 2017; Kim et al., 2016; Power et al., 2015). Moreover, some epidemiological studies has proved that noise pollution and air pollution can cause mental disorder as in (Markevych et al., 2017; Thiering et al., 2016; Hystad et al., 2014). However, some epidemiological research on psychological effects or mental disorder suggested that there is no consistency on the results because there is differences in terms of exposure of the noise (Ma et al., 2018; Dzhambor et al., 2017).

\section{Method of Data Analysis}

Probability distribution models have been used in different scenarios, for analysis and prediction processes in time-series modeling, reliability engineering, wind speed, rainfall, environmental modeling, river discharges, air quality, and health among others. Anwar and Bibi (2018) had presented that for the analysis of lifetime data, it is important to fit the data by a statistical model. Philip et al., (2019) identified the selection of the most suitable probability distribution model and related parameter estimation process, as a fundamental step in statistical analysis. In the literature, many commonly used probability distribution models including normal, lognormal, Weibull, gamma, generalized extreme value, lognormal, and normal distribution have been explained.

A normal distribution has been described as the commonly used probability distribution for its simplicity of having easily identifiable parameters mean and variance, and for the reason that most large. However, its symmetric nature and excess kurtosis of 0 , might not be true for certain natural phenomena (Alam et al., 2018).

Gamma distribution is one of the most used distribution models for special cases in different situations such as exponential and Chi-square (Ramos et al., 2019). The Probability distribution function for a gamma distribution model with two parameters $\infty$ and $\beta$ is usually given by

$$
f(x, \beta, \alpha)=\frac{1}{\gamma(\infty) \beta^{\infty}} x^{\infty-1} e^{-\frac{x}{p}} ; x, \infty, \beta>0
$$

Where $\beta$ is the scale parameter and $\infty$ is the shape parameter. 
The log-normal distribution function has been described as a highly skewed distribution for the logarithm of the variable. The probability distribution function for a log-normal distribution model with $\mu$ and $\sigma$ and s parameters is usually given by

$f\left(x ; \mu, \sigma^{2}\right)=\frac{1}{\sqrt{2 \pi \sigma^{2}}} e^{-(\ln x-\mu)^{2} / 2 \sigma^{2}}$

$x, \mu, \sigma>0$

Where $\mu$ is the location parameter and $\sigma^{2}$ is the scale parameter and also the standard deviation of the distribution.

The probability distribution function for the Weibull distribution model with two parameters $\infty$, and $\beta$ parameters is generally given by

$f(x, \infty, \beta)=\frac{\infty}{\beta}\left(\frac{x}{\beta}\right)^{\infty-1} e^{-(x / \beta)^{\infty} ; \infty>0, \beta>0}$

Where $\infty$, is the shape parameter and $\beta$ is the scale parameters.

According to Aldahlan et al., (2020) the Weibull distribution can prove adequate fits for most of the lifetime data, except those having experimental hazard rates with non-monotone forms. This limitation has motivated more flexible alternatives in terms of modelling, such extended, and beta the modified, the exponentiated, among others, and the more recently, a very flexible extension of the Weibull distribution called the exponentiated power generalized Weibull (EPGW) distribution.

The cumulative distribution function (cdf) of the EPGW distribution with parameters $\alpha, \beta, \lambda$, and $\mu$ is given by

$$
G_{E P G W}(x ; \alpha, \beta, \lambda, \mu)=\left[1-e^{1-\left(1+\lambda x^{\mu}\right)}\right]^{\beta}, x>0
$$

Where $\lambda>0$ is a scale parameter, and $\mu, \alpha, \beta$ are shape parameters

Prior research by Ramos et al., (2019) revealed that Generalized Gamma (GG) distribution models have been effectively applied in diverse areas, such as data processing, reliability, and meteorology, to mention but a few. Accordingly, GG distribution comprises of various sub-models such as the Weibull, log-normal, gamma, and half-normal, Maxwell-Boltzmann, Nakagami-m, Rayleigh, and Chi distributions. Quite a lot of classical methods have been employed for estimating the unknown parameters of probability distributions functions in the literature. Several types of research viewed the selection of suitable distribution model functions and its parameter estimation procedure as an active and challenging research area currently. Philip et al., (2019) had explained that the identification of Probability Distribution Models depends on the characteristics of available discharge data, followed by event sample variable election, then the estimation and the identification of the best distribution model 
suited for the estimation. Philip et al., (2019) considered maximum likelihood (ML) estimation, goodness-of-fit (GoF) tests-based analysis, and information criteria-based selection approach as the most suitable distribution functions models that are best suited for the estimation of maximum, minimum, and mean Parameters.

The maximum likelihood (ML) estimation method has been described as the commonly used estimators that give a minimum variance estimate of parameters, asymptotically normal, and asymptotically efficient.

For gamma distribution the maximum likelihood estimators $\bar{\infty}$ and $\bar{\beta}$ are given by simultaneous equations,

$\log \bar{\infty}-\varphi \bar{\infty}=\log \left[\frac{\bar{x}}{\left(\pi_{i=1}^{n} x_{1}\right)^{1 / n}}\right]$

$\bar{\beta}=\frac{\bar{x}}{\bar{\infty}}$

Where $\varphi(\stackrel{\equiv}{\equiv})=\frac{d}{d x}[\log \gamma(\infty)]=\frac{d \gamma(\infty) d \infty}{\gamma(\infty)}$

Which is the gamma function with an argument $\bar{\infty}$

Log normal distribution has the maximum likelihood parameter estimates for $\bar{\mu}$ and $\sigma^{2}$ given by;

$$
\begin{aligned}
& \bar{\mu}=\frac{1}{n} \sum_{i=1}^{n} \log x_{i} \\
& \sigma^{2}=\frac{1}{n-1} \sum_{i=1}^{n}\left[\log \left(x_{i}-\mu^{2}\right)\right]
\end{aligned}
$$

Weibull distribution has the maximum likelihood estimators $\bar{\infty}$ and $\bar{\beta}$ of the shape and scale parameters determined by;

$$
\begin{aligned}
& \bar{\infty}=\frac{n}{1 / \beta^{n}\left[\frac{1}{n} \sum_{i=1}^{n} x_{i}^{\infty}\right] \log x-\sum_{i=1}^{n} \log x} \\
& \bar{\beta}=\left[\frac{1}{n} \sum_{i=1}^{n} x_{i}^{\infty}\right]
\end{aligned}
$$

Goodness-of-fit tests-based statistical analysis and procedures are used for checking the validity of a specified probability distribution model.

It involves checking the normality by graphical methods, numerical methods, and proper normality tests (Alam et al., 2018). This approach first matches the raw dataset to more than one probability distributions model of interests 
then, the goodness-of-fit tests conducted to determine the distribution that best fits the data. To enable the user to describe the behaviour of the dataset, the best-fitted distribution is essential. Philip et al., 2019 identified the theory of GoF test statistics that are generally accepted for checking the adequacy of probability distributions models, given by

$$
x^{2}=\sum_{j=1}^{N} \frac{\left(O_{j}(Q i)-E_{j}(Q)\right)^{2}}{E_{j}(Q)}
$$

Where $\mathrm{Oj}(\mathrm{Q})$ is the frequency of the observed value of the jth class, $\mathrm{N}$ is the number of frequency classes, and $\mathrm{Ej}$ (Q) signifies the expected frequency value of the jth class.

The method of moments (MM) is one of the widely and commonly used estimators for estimating parameters in statistical distribution models. It is normally used mainly for its simplicity (Ramos et al., 2019). Alam et al., 2018 had explained that to calculate the parameters by using MM, the sample mean to say $\mathrm{X}$, standard deviation s and coefficient of skewness are;

$$
\begin{aligned}
& \bar{X}=\frac{1}{n} \sum_{i=1}^{n} X_{i} \\
& \sigma=\sqrt{\frac{1}{n-1} \sum_{i=1}^{n}\left(X_{i}-\bar{X}\right)^{2}} \\
& \gamma=\frac{n \sum_{i=1}^{n}\left(X_{i}-\bar{X}\right)^{3}}{(n-1)(n-2) S^{3}}
\end{aligned}
$$

Where $\mathrm{n}$ is the number of observations in the dataset, $\mathrm{i}$ is the number of observations, and $\mathrm{Xi}$ is the observed data. In addition to Alam et al., (2018) showed that log-normal distribution can be estimated using MM estimators, with two parameters expressed as follows:

$$
\begin{gathered}
\sigma_{\gamma}=\left[\ln \left(1+\frac{\sigma^{2} X}{\mu^{2} X}\right)\right]^{1 / 2} \\
\mu_{\gamma}=\ln (\mu X)-\frac{1}{2} \sigma^{2} \gamma
\end{gathered}
$$

Where, $\sigma_{\gamma}$ is the standard deviation and $\mu_{\gamma}$ is the mean for the log-normal distribution. Weibull distribution parameters can be estimated by using the MM estimators given by

$$
\mu=\alpha \Gamma\left(1+\frac{1}{k}\right)
$$


$\sigma^{2}=\alpha^{2}\left\{\Gamma\left(1+\frac{2}{k}\right)-\left[\Gamma\left(1+\frac{1}{k}\right)\right]^{2}\right\}$

Where $\mu$ is the scale parameter and $\sigma^{2}$ is the shape parameter for the Weibull distribution.

Three probability density functions shall be employed to analyse the noise level measured after which the best fit model was applied to determine the probability of the exceeding critical point.

a. Gamma distribution, b. Lognormal distribution, c. Weibull distribution

Different probability distribution models shall be employed to model the noise and best model shall be selected to determine the probability of the exceeding critical point.

\section{(a) Gamma distribution}

Let the RFF measured (X) denotes the random variable, the parameters of the probability function can be obtained using expression (1)

$$
\mathrm{f}(\mathrm{x}, \beta, \alpha)=\frac{1}{\gamma^{(\infty)} \beta^{\infty}} x^{\infty-1} e^{-\frac{x}{p}} ; x, \infty, \beta>0
$$

Where $\beta$ is the scale parameter and $\infty$ is the shape parameter, and its parameters of the maximum likelihood may be estimated using equation (21) and (22) as,

$\log \infty-\varphi(\infty)=\log \left[\frac{\bar{x}}{\left(\pi_{i=1}^{n} x_{1}\right)^{1 / n}}\right]$

$\bar{\beta}=\frac{\bar{x}}{-\overline{--}}$

Where $\varphi(\bar{\infty})=\varphi(-\infty)=\frac{d}{d x}[\log \gamma(\infty)]=\frac{d_{\gamma}(\infty) d_{\infty}}{\gamma^{(\infty)}}$

Which is the Gamma function with an argument $\overline{-}$

\section{(b) Lognormal distribution}

If $\mathrm{x}$ is lognormally distributed then $\ln (\mathrm{x})$ is normally distributed. Therefore, the PDF is obtained using (23) as

$$
f\left(x ; \mu, \sigma^{2}\right)=\frac{1}{\sqrt{2 \pi \sigma^{2}}} e^{-(\ln x-\mu)^{2 / 2 \sigma^{2}}}
$$

$x, \mu, \sigma>0$

Where $\mu$ is the location and $\sigma^{2}$ is the scale parameters respectively then the maximum likelihood parameter $\mu$ and $\sigma$ can be estimated using equation (23) and (24) 
$\mu=\left(\frac{1}{n}\right) \sum_{i=1}^{n} \log x_{i}$

$$
\sigma^{2}=\frac{1}{n-1} \sum_{i=1}^{n}\left[\log \left(x_{i}-\mu^{2}\right)\right]
$$

\section{(c) Weibull distribution}

$\mu \mathrm{X}$ is Weibull distributed the parameters of the PDF is estimated using equation (26), given by

$$
f(x, \infty, \beta)=\frac{\infty}{\beta}\left(\frac{x}{\beta}\right)^{\infty-1} e^{-(x / \beta)^{\infty}} ; \infty>0, \beta>0
$$

Where $\infty$ is the space and $\beta$ is the scale parameters respectively. Its maximum likelihood is going to determined using equations (28) and (29)

$$
\begin{aligned}
& \bar{\infty}=\frac{n}{\left(1 / \beta^{n}\right) \sum_{i=1}^{n} x_{i}^{--} \log x-\sum_{i=1}^{n} \log x-} \\
& \hat{\beta}=\left[\left(\frac{1}{n}\right) \sum_{i=1}^{n} x_{i}^{--}\right]
\end{aligned}
$$

\section{Probability of exceeding critical point}

The probability of exceeding the critical point of the RFF may be obtained from the best fit model and it shall be calculated using equation (29) as,

$\operatorname{Pr}(\mathrm{X}>\mathrm{x})=1-\operatorname{Pr}(\mathrm{X} \leq \mathrm{x})=1-\int_{-\infty}^{x} f(x) d x$

\section{Conclusion}

Noise pollution (NP) is considered as the third most hazardous type of environmental pollution. High noise pollution in residential areas is recognized in the world as a major threat to health and affecting liveability. In this research work we have conducted a thorough review on the hazard of noise on human health and explore the level of risk regarding to the level of sound and finally identified the diseases that may be caused if you are exposed to the certain level of noise.

\section{Declarations}

\section{Source of Funding}

This research did not receive any grant from funding agencies in the public, commercial, or not-for-profit sectors.

\section{Competing Interests Statement}

The authors declare no competing financial, professional and personal interests. 


\section{Ethical Approval}

Ethical approval for this research was given based on institutional guidelines.

\section{Consent to participate}

The consent to participate in this research was sought for and approved by the subjects to be used.

\section{Consent for publication}

We declare that we consented for the publication of this research work.

\section{Availability of data and material}

Authors are willing to share data and material according to the relevant needs.

\section{Reference}

Alam, M. A., Emura, K., Farnham, C., \& Yuan, J. (2018). Best-fit probability distributions and return periods for maximum monthly rainfall in Bangladesh. Climate, 6(1), 9.

Aldahlan, M. A., Jamal, F., Chesneau, C., Elbatal, I., \& Elgarhy, M. (2020). Exponentiated power generalized Weibull power series family of distributions: Properties, estimation and applications. Plos one, 15(3), e0230004.

Alimohammadi, I., Soltani, R., Sandrock, S., Azkhosh, M., \& Gohari, M. R. (2013). The effects of road traffic noise on mental performance. Iranian journal of environmental health science \& engineering, 10(1), 18.

Ali, S. A. (2011). Industrial noise levels and annoyance in Egypt. Applied acoustics, 72(4), 221-225.

Alnuman, N., \& Ghnimat, T. (2019). Awareness of noise-induced hearing loss and use of hearing protection among young adults in Jordan. International journal of environmental research and public health, 16(16), 2961.

Anwar, M., \& Bibi, A. (2018). The half-logistic generalized Weibull distribution. J. of prob. and statistics, 2018.

Babisch, W. (2014). Updated exposure-response relationship between road traffic noise and coronary heart diseases: A meta-analysis. Noise and Health, 16(68), 1-9

Babisch, W., et al., (2014). Associations between traffic noise, particulate air pollution, hypertension, and isolated systolic hypertension in adults: The KORA study. Environmental Health Perspectives, 122(5), 492-498.

Banerjee, D., Das, P., \& Foujdar, A. (2014). Association between road traffic noise and prevalence of coronary heart disease. Environmental Monitoring and Assessment, 186(5), 2885-2893.

Basner, M., Babisch, W., Davis, A., Brink, M., Clark, C., Janssen, S., \& Stansfeld, S. (2014). Auditory and non-auditory effects of noise on health. The lancet, 383(9925), 1325-1332.

Basner, M., \& McGuire, S. (2018). World Health Organisation [WHO] environmental noise guidelines for the European Region: a systematic review on environmental noise and effects on sleep. International Journal of Environ Res Public Health, 15(3), E519 (http://www.mdpi.com/1660-4601/15/3/519/htm 
Basner, M., Riggs, D.W., \& Conklin, D. J. (2020). Environmental determinants of hypertension and diabetes mellitus: sounding off about the effects of noise. Journal of the American Heart Association, 9(6), https://doi.org/10.1161/JAHA.120.016048

Basner, M., Witte, M., \& McGuire, S. (2019). Aircraft noise effects on sleep results of a pilot study near Philadelphia international airport. Int. J. Environ. Res. Public Health, 16(17), 3178. https://doi.org/10.3390/ijerph16173178.

Beutel, M. E., Jünger C., Klein, E. M., Wild, P., Lackner, K., Blettner, M., Münzel, T. (2016). Noise annoyance is associated with depression and anxiety in the general population- The contribution of aircraft noise. PLoS ONE 11(5), e0155357. doi:10.1371/journal.pone.0155357.

Brown, A. L., Lam, K. C., \& van Kamp, I. (2015). Quantification of the exposure and effects of road traffic noise in a dense Asian city: a comparison with western cities. Environmental health, 14(1), 22.

Chamkori, A., Shariati, M., Moshtaghi, D., \& Farzadinia, P. (2016). Effect of noise pollution on the hormonal and semen analysis parameters in industrial workers of Bushehr, Iran. Crescent J. Med. Biol. Sci, 3, 45-50.

Clara G. Sears, Joseph M., Braun, Patrick H., Ryan, Yingying X., Erika F., Werner B.P., Lanphear, Gregory A., Wellenius (2018) The association of traffic related air pollution with maternal blood pressure and hypetensive disorders of pregnancy in the home study cohort. Environment International 121. 574-581.

Clark, C., \& Paunovic, K. (2018). WHO Environmental noise guidelines for the European Region: A systematic review on environmental noise and quality of life, wellbeing and mental health. International journal of environmental research and public health, 15(11), 2400.

Cesaroni, G., Forastiere, F., Stafoggia, M., Andersen, Z. J., Badaloni, C., Beelen, R., \& Fratiglioni, L. (2014). Long term exposure to ambient air pollution and incidence of acute coronary events: prospective cohort study and meta-analysis in 11 European cohorts from the ESCAPE Project. Bmj, 348, f7412.

Correia, A., Peters, J., Levy, J., Melly, S., \& Dominici, F. (2013). Residential exposure to aircraft noise and hospital admissions for cardiovascular diseases: multi-airport retrospective study. The BMJ, 347

Delaney, L. J., Currie, M. J., Huang, H. C., Lopez, V., \& Haren, F. V. (2018). “They can rest at home”: an observational study of patients' quality of sleep in an Australian hospital. BMC Health Services Research, 18(524), https://doi.org/10.1186/s12913-018-3201-z

Delaney, L. J., Haren, F. V., \& Lopez, V. (2015). Sleeping on a problem: the impact of sleep disturbance on intensive care patients - a clinical review. Annals of Intensive Care, 5(3), DOI 10.1186/s13613-015-0043-2.

De Kluizenaar, Y., van Lenthe, F., Visschedijk, A., Zandveld, P., Miedema, H. \& Mackenbach, J. (2013). Road traffic noise, air pollution components and cardiovascular events. Noise \& Health, 15(67), 388-397.

De Souza, T. C. F., Périssé, A. R. S. \& Moura, M. (2015). Noise exposure and hypertension: investigation of a silent relationship. BMC Public Health 15(328) https://doi.org/10.1186/s12889-015-1671-z 
Asian Journal of Basic Science \& Research Volume 3, Issue 2, Pages 61-76, April-June 2021

Dreger, S., Schüle, S. A., Hil, L. K., \& Bolte, G. (2019). Social Inequalities in Environmental Noise Exposure: A Review of Evidence in the WHO European Region. International Journal of Environmental Research and Public Health, 16, (1011), 1-15, doi:10.3390/ijerph16061011.

Dzhambov, A. M., Markevych, I., Tilov, B., Arabadzhiev, Z., Stoyanov, D., Gatseva, P., \& Dimitrova, D. D. (2018). Pathways linking residential noise and air pollution to mental ill-health in young adults. Environ. Res. 166, $458-465$.

Dzhambor A., Tilov B., Markevych I., Dimitrova D. (2017) Residential road traffic noise and general mental health in youth: the role of noise annyonce, neighborhood restorative quality physical activity and social cohesion as potential mediators. Enveron. Int. 109, 1-9.

Eisenberg, M.L., Chen, Z., Ye, A., Buck Louis, G.M., (2015). Relationship between physical occupational exposures and health on semen quality: data from the longitudinal investigation of fertility and the environment study. Fertil. Seril. 103, 1271-1277.

Evandt, J., Oftedal, B., Krog, N.H., Skurtveit, S., Nafstad, P., Schwarze, P. E., Aasvang, G. M. (2017). Road traffic noise and registry-based use of sleep medication. Environ Health 16(110).

Fajar, J. K., Susanti, M., Pikir, B. S., Saka, P. N. B., Sidarta, E. P., Tamara, F. Heriansyah, T. (2019). The association between angiotensin II type 1 receptor A1166C gene polymorphism and the risk of essential hypertension: a meta-analysis. Egyptian Journal of Medical Human Genetics, 20(14).

Farzadinia, P., Bigdeli, M., Akbarzadeh, S., Mohammadi, M., Daneshi, A., \& Bargahi, A. (2016). Effect of noise pollution on testicular tissue and hormonal assessment in rat. Andrologia, 48(9), 957-961.

Foraster, M., Eze, I. C., Vienneau, D., Schaffner, E., Jeong, A., Heritier, H., Probst-Hensch, N. (2018). Long-term exposure to transportation noise and its association with adiposity markers and development of obesity. Environment International, 121, 879-889, https://doi.org/10.1016/j.envint.2018.09.057

Frei, P., Mohler, E., \& Röösli, M. (2014). Effect of nocturnal road traffic noise exposure and annoyance on objective and subjective sleep quality. International J. of Hygiene and Environmental Health, 217(2-3), 188-195.

Göldi, M., \& Rasch, B. (2019). Effects of targeted memory reactivation during sleep at home depend on sleep disturbances and habituation. npj Science. Learning. 4(5), https://doi.org/10.1038/s41539-019-0044-2

Guzik, T. J., \& Channon, K. M. (2017). Linking noise to cardiovascular disease pathogenesis. European Heart Journal, 38(37), 2850-2852, https://doi.org/10.1093/eurheartj/ehx217

Hahad, O., Kroller-Schon, S., Daiber, A., \& Munzel, T. (2019). The Cardiovascular effects of noise. Duetsches Arztablatt International, 116(14), 245-250, doi: 10.3238/arztebl.2019.0245

Halonen, J. L., Hansell, A.L, Gulliver (2015). Road traffic noise is associated with increased cardiovascular morbidity and mortality and all-cause mortality in London. European Heart Journal http://dx.doi.org/10.1093/eurheartj/ehv216 
Hart, R.J., (2016). Physiological aspects of female fertility: role of environment, modern lifestyle and genetics. Physiol. Rev. 96, 873-909.

Helbich, M. (2018). Mental Health and Environmental Exposures: An Editorial. International Journal of Environmental Research and Public Health, 15(2207), 11-4, doi:10.3390/ijerph15102207

Helzner, E. P., \& Contrera, K. J. (2016). Type 2 diabetes and hearing impairment. Curr Diab Rep, 16(3), https://doi.org/10.1007/s11892-015-0696-0

Honda, T., Eliot, M.N., Eaton, C.B., Whistel, E., Stewart, J.D., Mu, L., Suh, H., Szpiro, A., Kaufman, J.D., Vedal, S., Wellenius, G.A., (2017). Long term exposure to residential ambient fine and coarse particulate matter and incident hypertension in post-menopausal women. Environ. Int. 105, 79-85.

Huang, D., Yu, Y. Y., \& Tu, C. (2019). Bilateral high-frequency hearing loss is associated with elevated blood pressure and increased hypertension risk in occupational noise exposed workers. PLoS ONE, (149), e0222135, doi:10.1371/journal.pone.0222135.

Ibrahim, M. M. (2018). Hypertension in developing countries: a major challenge for the future. Current hypertension reports, 20(5), 38 .

Jalali, M., Hemadi, M., Saki, G., Sarkaki, A., (2013). A study of spermatogenesis fetal testis exposed noise stress during and after natal period in rat. Pak J. Biol. Sci. 16, 1010-1015.

Jensen, H. A. R., \& Ekholm, O. (2019). Neighbour noise annoyance is associated with various mental and physical health symptoms: results from a nationwide study among individuals living in multistorey housing. BMC Public Health, 19(1508).

Kenz, J., (2013). Endocrine-disrupting chemicals and male reproductive health. Reprod. Biom. online 26, 440-448. Khosravipour, M., Khosravi, F., Ashtarian, H., Rezaei, M., Moradi, Z., \& Mohammadi Sarableh, H. (2020). The effects of exposure to different noise frequency patterns on blood pressure components and hypertension. International archives of occupational and environmental health.

Langat, P. K., Kumar, L., \& Koech, R. (2019) Identification of the most suitable probability distribution models for maximum, minimum, and mean streamflow. Water, 11(4), 734.

Lavigne, E., Yasseen III, A. S., Stieb, D. M., Hystad, P., et al., (2016). Ambient air pollution and adverse birth outcomes: differences by maternal comorbidities. Environmental research, 148, 457-466.

Le, T. N., Straatman, L. V., Lea, J., \& Westerberg, B. (2017). Current insights in noise-induced hearing loss: a literature review of the underlying mechanism, pathophysiology, asymmetry, and management options. Journal of Otolaryngology-Head \& Neck Surgery, 46(1), 41.

Lie, A., Skogstad, M., Johannessen, Tynes, T., Mehlum, I. S., Nordby, K., Engdahl, B., \& Tambs, K. (2016). Occupational noise exposure and hearing: a systematic review. Int Arch Occup Environ Health 89, 351-372 https://doi.org/10.1007/s00420-015-1083-5 
Lim, C. C., \& Thurston, G. D. (2019). Air Pollution, Oxidative Stress, and Diabetes: a Life Course Epidemiologic Perspective. Current Diabetes Reports, 19(58) https://doi.org/10.1007/s11892-019-1181-y

Lim, J., Kweon, K., Kim, H., Cho, S. W., Park, J., \& Sim, C. S. (2018). Negative impact of noise and noise sensitivity on mental health in childhood. A Bimonthly Interdisciplinary International Journal, 20(96), 199-211, doi:10.4103/nah.NAH_9_18

Liu, L., Huang, Y., Fang, C., Xhang, H., Yang, J., Auan, C., Wang, J. (2018). Chronic noise-exposure exacerbates insulin resistance and promotes the manifestations of the type 2 diabetes in a high-fat diet mouse model. PLoS ONE, (13), e0195411, doi:10.1371/journal.pone.0195411

Li, X., Dong, Q., Wang, B., Wang, B., Song, H., Wang, S., \& Zhu, B. (2019). The Influence of occupational noise exposure on cardiovascular and hearing conditions among industrial workers. Sci Rep 9(11524) https://doi.org/10.1038/s41598-019-47901-2

Lusk, S. L., McCullagh, M., Dickson, V. V., \& Xu, J. (2016). Position statement: Harmful effects of environmental noise exposures. American Academy of Nursing on Policy, 395-396.

Ma J., Li C., Kwan M. P., Chai Y., (2018) A multi-level analysis of perceived noise pollution geographic context and mental health in Beijing. Internationl Journal of Environ. Res. Public health 15, 1479.

McGuire, S., Müller, U., Elmenhorst, E. M., \& Basner, M. (2016). Inter-individual differences in the effects of aircraft noise on sleep fragmentation. SLEEP, 39(5), 1107-1110. http://dx.doi.org/10.5665/sleep.5764

Min, K. \& Min, J. (2017). Exposure to environmental noise and risk for male infertility: A population-based cohort study, Environmental Pollution, 226, 118-124.

Mocarelli, P., Gerthoux, P.M., Patterson J.R., D.G., Milani, S., Limonta, G., Bertona, M., Signorini, S., Tramacere, P., Colombo, L., Crespi, C., Brambilla E., Sarto, C., Carreri, V., Sampson, E.J., Turner, W.E., Needham, L.L., (2008). Dioxin exposure from infancy through puberty, produces endocrine distruption and effects human semen quality. Environ. Health perspect. 116, 70-77.

Münzel, T., gori T., Babisch, W., \& Basner, M. (2014). Cardiovascular effects of environmental noise exposure. European heart Journal, 35(13), 829-836.

Münzel, T., Schmidt, F. P., Steven, S., Herzog, J., Daiber, A., \& Sørensen, M. (2018). Environmental noise and the cardiovascular system. Journal of the American College of Cardiology, 71(6), 688-697.

Münzel, T., Sørensen, M., Schmidt, F., Schmidt, E., Steven, S., Kröller-Schön, S., \& Daiber, A. (2018). The adverse effects of environmental noise exposure on oxidative stress and cardiovascular risk. Antioxidants \& redox signaling, 28(9), 873-908.

Oguntunde, P. E., Okagbue, H. I., Oguntunde, O. A., \& Odetunmibi, O. O. (2019). A study of noise pollution measurements and possible effects on public health in ota metropolis, Nigeria. Open Access Macedonian Journal of Medical Sciences, 7(8), 1391. 
Orban, E., McDonald, K., Sutcliffe, R., Hoffmann, B., Fuks, K. B., Dragano, N., Moebus, S. (2016). Residential road traffic noise and high depressive symptoms after five years of follow-up: Results from the Heinz Nixdorf Recall Study. Environ. Health Perspect. 124, 578-585.

Otoghile, B., Ediale, J., Ariyibi, N. O., Otoru, O., Kuni, J., \& Maan, N. (2019). Effect of occupational noise on blood pressure, Global Journal of Health Science, 11(3), doi: 10.5539/gjhs.v11n3p63

Ramos, P. L., Nascimento, D. C., Ferreira, P. H., Weber, K. T., Santos, T. E., \& Louzada, F. (2019). Modeling traumatic brain injury lifetime data: Improved estimators for the Generalized Gamma distribution under small samples. PLoS one, 14(8), e0221332.

Rapisarda, V., Ledda, C., Ferrante, M., Fiore, M., Cocuzza, S., Bracci, M., \& Fenga, C. (2016). Blood pressure and occupational exposure to noise and lead $(\mathrm{Pb})$ A cross-sectional study. Tox. and ind. health, 32(10), 1729-1736.

Recio, A., Linares, C., Banegas, J. R., \& Diaz, J. (2016). Road traffic noise effects on cardiovascular, respiratory, and metabolic health: an integrative model of biological mechanisms. Environ. Res. 146, 359-370.

Rudolph, K. E., Shev, A., Paksarian, D., Merikangas, K. R., Mennitt, D. J., James, P., \& Casey, J. A. (2019). Environmental noise and sleep and mental health outcomes in a nationally representative sample of urban US adolescents. Environmental Epidemiology (Philadelphia, Pa.), 3(4), e056.

Russ, S. A., Tremblay, K., Halfon, N., \& Davis, A. (2018). A life course approach to hearing health. In Handbook of life course health development (pp. 349-373). Springer, Cham.

Sakhvidi, M. J. Z., Sakhvidi, F. Z., Mehrparvar, A. H., Foraster, M., \& Dadvand, P. (2018). Association between noise exposure and diabetes: A systematic review and meta-analysis. Environmental research, 166, 647-657.

Sareen, A., \& Singh, V. (2014). Noise induced hearing loss: A review. Otolaryngology online journal, 4(2), 17-25.

Shin, S., Bai, L., Oiamo, T. H., Burnett, R. T., Weichenthal, S., Jerrett, M., \& Chen, H. (2020). Association between road traffic noise and incidence of diabetes mellitus and hypertension in Toronto, Canada: a population-based cohort study. Journal of the American Heart Association, 9(6), e013021.

Stansfeld, S. A. (2015). Noise effects on health in the context of air pollution exposure. International journal of environmental research and public health, 12(10), 12735-12760.

Tabraiz, S., Ahmad, S., Shehzadi, I., \& Asif, M. B. (2015). Study of physio-psychological effects on traffic wardens due to traffic noise pollution; exposure-effect relation. J. of env. health sci. and engineering, 13(1), 30.

Taban, E., Mortazavi, S. B., Vosoughi, S., \& Khavanin, A. (2016). Investigating the effects of noise exposure on intensification of diabetes mellitus, serum glucose, cortisol level and body weight of the male mice. Journal of Paramedical Sciences (JPS) Autumn, 7(4), 11-20.

Tassi, P., Rohmer, O., Bonnefond, A., Margiocchi, F., Poisson, F., \& Schimchowitsch, S. (2013). Long term exposure to nocturnal railway noise produces chronic signs of cognitive deficits and diurnal sleepiness. Journal of Environmental Psychology, 33, 45-52. 
Tobías, A., Recio, A., Díaz, J., \& Linares, C. (2015). Health impact assessment of traffic noise in Madrid (Spain). Environmental research, 137, 136-140.

Tzivian, L., Winkler, A., Dlugaj, M., Schikowski, T., Vossoughi, M., Fuks, K., ... \& Hoffmann, B. (2015). Effect of long-term outdoor air pollution and noise on cognitive and psychological functions in adults. International journal of hygiene and environmental health, 218(1), 1-11.

Vested, A., Giwercman, A., Bonde, J.P., Toft, G., (2014). Persistent organic pollutants and male reproductive health. Asian Journal of Anthology 16, 71-80.

Vivanco-Hidalgo, R. M., Avellaneda-Gómez, C., Dadvand, P., Cirach, M., Ois, Á., González, A. G., \& Cuadrado-Godia, E. (2019). Association of residential air pollution, noise, and greenspace with initial ischemic stroke severity. Environmental research, 179, 108725.

Vivanco-Hidalgo, R. M., Wellenius, G. A., Basagaña, X., Cirach, M., González, A. G., de Ceballos, P., \& Alastuey, A. (2018). Short-term exposure to traffic-related air pollution and ischemic stroke onset in Barcelona, Spain. Environmental Research, 162, 160-165.

Weihofen, V. M., Hegewald, J., Euler, U., Schlattmann, P., Zeeb, H., \& Seilder, A. (2019). Aircraft noise and risk of stroke: a systematic review and meta-analysis. Dtsch Arztebl Int. 116(14), 237-244.

Yang, B. Y., Qian, Z. M., Li, S., Chen, G., Bloom, M. S., Elliott, M., \& Chen, D. (2018). Ambient air pollution in relation to diabetes and glucose-homoeostasis markers in China: a cross-sectional study with findings from the 33 Communities Chinese Health Study. The Lancet Planetary Health, 2(2), e64-e73.

Zhu, Y., Zhang, C., Liu, D., Ha, S., Kim, S. S., Pollack, A., \& Mendola, P. (2017). Ambient air pollution and risk of gestational hypertension. American journal of epidemiology, 186(3), 334-343. 